\title{
Sulforaphane reverses chemo-resistance to temozolomide in glioblastoma cells by NF-кB-dependent pathway downregulating MGMT expression
}

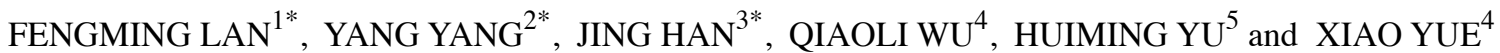 \\ ${ }^{1}$ Department of Radiation Oncology, Tianjin Hospital, Tianjin; ${ }^{2}$ Department of Orthopedics, Tianjin Hospital, \\ Tianjin; ${ }^{3}$ Department of Gastroenterology, The Fifth Central Hospital of Tianjin, Tianjin; ${ }^{4}$ Tianjin Huanhu \\ Hospital, Tianjin Neurosurgery Institute, Tianjin; ${ }^{5}$ Key Laboratory of Carcinogenesis and Translational \\ Research, Department of Radiotherapy, Peking University Cancer Hospital, Beijing, P.R. China
}

Received October 3, 2015; Accepted November 5, 2015

DOI: 10.3892/ijo.2015.3271

\begin{abstract}
The survival benefits of patients with glioblastoma (GBM) remain unsatisfactory due to the intrinsic or acquired resistance to temozolomide (TMZ). We elucidated the mechanisms of sulforaphane (SFN) reverse TMZ resistance in TMZ-inducing cell lines by inhibiting nuclear factor- $\kappa \mathrm{B}$ $(\mathrm{NF}-\kappa \mathrm{B})$ transcriptional activity. TMZ-resistant cell lines (U87-R and U373-R) were generated by stepwise (6 months) exposure of parental cells to TMZ. Luciferase reporter assay, biochemical assays and subcutaneous tumor establishment were used to characterize the antitumor effect of SFN. MGMT expression and $50 \%$ inhibiting concentration $\left(\mathrm{IC}_{50}\right)$ values of TMZ in GBM cell lines were assessed. Next, we established that U87-R and U373-R cells presenting high $\mathrm{IC}_{50}$ of TMZ, activated $\mathrm{NF}-\kappa \mathrm{B}$ transcription and significantly increased MGMT expression compared with untreated cells. Furthermore, we revealed that SFN could significantly suppress proliferation of TMZ-resistant GBM cells. In addition, SFN effectively inhibited activity of $\mathrm{NF}-\kappa \mathrm{B}$ signaling pathway and then reduced MGMT expression to reverse the chemo-resistance to TMZ in T98G, U87-R and U373-R cell lines. Sequential combination with TMZ synergistically inhibited survival capability and
\end{abstract}

Correspondence to: Dr Xiao Yue, Tianjin Huanhu Hospital, Tianjin Neurosurgery Institute, 122 Qixiangtai Road, Tianjin 300060, P.R. China

E-mail: yuexiaolfm@163.com

Dr Huiming Yu, Key Laboratory of Carcinogenesis and Translational Research, Department of Radiotherapy, Peking University Cancer Hospital, Beijing, P.R. China

E-mail: huiming740512@163.com

*Contributed equally

Key words: glioblastoma, sulforaphane, temozolomide, nuclear factor- $\kappa \mathrm{B}, \mathrm{O6}-\mathrm{methylguanine-DNA}$ methyltransferase increased the induction of apoptosis in TMZ-resistant GBM cells. Finally, a nude mouse model was established with U373-R cell subcutaneous tumor-bearing mice, and results showed that SFN could remarkably suppress cell growth and enhance cell death in chemo-resistant xenografts in the nude mouse model. Collectively, the present study suggests that the clinical efficacy of TMZ-based chemotherapy in TMZ-resistant GBM may be improved by combination with SFN.

\section{Introduction}

Prognosis of glioblastoma (GBM) is still dismal despite multimodality treatments applied such as aggressive surgical resection and adjuvant chemo-radiotherapy (1-3). A major advance in GBM therapy as an advantageous treatment is the involvement of DNA alkylating agent temozolomide (TMZ) (4). $\mathrm{TMZ}$, an orally administered alkylating agent with relatively low toxicity, exerts the antitumor activity by interfering with DNA replication. Many randomized clinical trials evidenced that TMZ-based chemo-therapy significantly improved quality of life and prolonged survival of GBM patients $(5,6)$. However, TMZ resistance of GBM is a key factor involved in poor responses and dismal prognosis. Previous studies have evidenced that the resistance to TMZ of molecular pathogenes in GBM is related to O6-methylguanine-DNA methyltransferase (MGMT), which can lead to the replication of DNA and the growth of GBM cells $(7,8)$.

The mechanism of action of MGMT involves the removal of alkyl groups from damaged DNA in a one-way suicide reaction by transferring them to an internal cysteine residue (9). The expression of MGMT varies widely in different kinds of tumor cells. It has been suggested that MGMT is the most important determinant of resistance to TMZ (10). Increasing data indicated prognosis of patients with high MGMT expression is much poorer than those with low expression. Moreover, MGMT overexpression was able to resist cell death induced by TMZ in both experimental and clinical settings $(11,12)$. Importantly, MGMT promoter methylation is an essential predictor which is associated with better clinical responses to chemoradiation and overall survival $(13,14)$. 
Several transcription factors have been suggested to be involved in the complex process of MGMT transcriptional regulation, including $\mathrm{p} 53, \mathrm{NF}-\kappa \mathrm{B}, \mathrm{HIF}-1 \alpha$, and AP-1 (15-17). $\mathrm{NF}-\kappa \mathrm{B}$ is a family of direct transcription factors which can bind to specific DNA sequences in target genes involving in immunoregulation, inflammation, growth, carcinogenesis and apoptosis $(18,19)$. Activated NF- $\mathrm{NB}$ can function as an oncogene in a variety of tumors to promote tumor cell proliferation and invasion, induce angiogenesis and metastasis, and prevent apoptosis $(20,21)$. It was also suggested that inhibition of $N F-\kappa B$ activity by suppressors could strongly enhance the apoptotic potential of the alkylating agent. A previous study showed that NF- $\kappa$ B subunit p65 induced the increase of MGMT expression, whereas NF- $\mathrm{BB}$ inhibitor abrogates the augmented expression of MGMT in HEK293 cells. MGMT is a target gene for $\mathrm{NF}-\kappa \mathrm{B}$ and plays an important role in $\mathrm{NF}-\kappa \mathrm{B}$-mediated chemo-resistance to alkylating agents (16). Therefore, inhibiting the NF- $\kappa \mathrm{B}-\mathrm{MGMT}$ pathway is a significant strategy to overcome TMZ-resistance.

Sulforaphane (SFN), a naturally-occurring member of the isothiocyanate (ITC) family, is ample in normally consumed cruciferous vegetables $(22,23)$. Recently, evidence from numerous epidemiological investigations demonstrated that the higher dietary intakes of cruciferous vegetables were associated with reduced risk of various cancers, such as mammary gland tumorigenesis, colonic aberrant crypt foci, stomach tumors, prostate, bladder and lung cancer (24). The underlying mechanisms of SFN in anticancer activity have been reported in many respects including detoxification enzymes, oxidative stress induction, checkpoint activation in DNA damage, and inhibition of histone deacetylase (HDAC) direct binding to cellular proteins (25). Previous reports suggested many survival signaling pathways could be blocked by SFN in various tumors. For example, SFN significantly suppressed the expression of phosphorylated c-Jun N-terminal kinase (p-JNK), phosphorylated extracellular signal-regulated kinases (p-ERK), p-Akt and $\beta$-catenin, and then interrupting the MAPK, PI3K/Akt and Wnt signaling pathway (26,27).

Increasing evidence shows an essential effect of SFN on growth inhibition and apoptosis induction in human cancer cells, and this research was performed to explore the sensitization of SFN to TMZ in TMZ-resistant GBM cells.

\section{Materials and methods}

Cell culture and reagents. Human GBM cell lines (T98G, U87, LN229, U373 and U251) were obtained from the China Academia Sinica Cell Repository, Shanghai, China. Human cells U373 and U87 were exposed to TMZ (Temodal, Schering-Plough, Whitehouse Station, NJ, USA) until stable TMZ-resistant subclones (U373-R and U87-R) were derived from the parental TMZ-sensitive cell lines. Both cells were exposed to stepwise increasing concentrations of TMZ (2-100 $\mu \mathrm{M})$ over a period of 6 months.

Antibodies against MGMT, p65, Ki-67, caspase-3 and MMP2/9 were obtained from Cell Signaling Technology (Danvers, MA, USA). SFN (St. Louis, MO, USA) was prepared in DMSO at the stock solution of $100 \mathrm{mM}$ and further diluted to appropriate concentration with cell culture medium immediately before use.
Western blot analysis and reverse transcription-polymerase chain reaction ( $R T-P C R)$ analysis. Cell proteins were separated by sodium dodecyl sulfate-polyacrylamide gel electrophoresis (SDS-PAGE) and then transferred onto polyvinylidene difluoride membranes (Millipore). Protein binding to the MGMT, Ki-67, MMP2/9, p65 and caspase-3 antibody (Santa Cruz Biotechnology, Inc.) was assessed by enhanced chemiluminescence and exposed to a chemiluminescent film.

Total RNA was isolated from GBM cells by the TRIzol method. Reverse transcription was performed using a reverse transcription kit (Qiagen), and the primers were synthesized by GenePharma (Shanghai, China) (28).

Cell viability assay. 3-(4,5-Dimethylthiazol-2-yl)-2,5diphenyltetrazolium bromide (MTT) (Sigma) was used to determine the cell viability and the $50 \%$ growth inhibitory concentration $\left(\mathrm{IC}_{50}\right)$ of $\mathrm{TMZ}$ or $\mathrm{SFN}$ in both parental and TMZ-resistant cell lines. Cells were cultured in 96-well plate at a density of $5 \times 10^{3}$ cells/well in medium containing $10 \%$ fetal bovine serum (FBS) and were incubated for $72 \mathrm{~h}$. Subsequently, TMZ was added to culture medium at final concentrations of $0,500,1000,2000,3000,4000,5000$ or $6000 \mu \mathrm{M}, \mathrm{SFN}$ was added at a final concentration of 0,5 , $10,20,30,40$ or $50 \mu \mathrm{M}$. After incubation for $48 \mathrm{~h}$, cells were detached by trypsinization and the viable cell population was determined using MTT. All experiments were done in triplicate.

Cell colony formation assay. U87-R, U373-R and T98G cells were seeded into 6-well plates and allowed to attach overnight. Cells were then treated with different concentration of SFN $(0,10$ or $25 \mu \mathrm{M})$ and colony formation assay was done as described (29). Only colonies with 50 or more cells were counted as surviving colonies under an inverted microscope.

Cell invasion assay. Cells were treated with different concentrations of SFN $(10,20$ or $30 \mu \mathrm{M})$, and after $8 \mathrm{~h} \mathrm{TMZ}(250 \mu \mathrm{M})$ was added. After $48 \mathrm{~h}$, the invasion ability of GBM cells was determined using Transwell plates (BD Biosciences, Bedford, MA, USA) according to the manufacturer's protocol.

Cell apoptosis assay. Cells cultured in 6-well plates for $24 \mathrm{~h}$ were treated with SFN $(10,20$ or $30 \mu \mathrm{M})$ and TMZ $(250 \mu \mathrm{M}$, after $8 \mathrm{~h}$ ) and cultured for additional $48 \mathrm{~h}$. For detection of apoptosis, the FITC Annexin V Apoptosis Detection kit (BD Pharmingen, San Jose, CA, USA) was used according to the manufacturer's protocol, and quantification of apoptosis was determined through measurement of caspase-3/7 activation using caspase-3/7 Detection in Living Cells kit (Biotium Inc., Hayward, CA, USA).

$N F-\kappa B$ transcription reporter assay. The Luciferase reporter (Stratagene, La Jolla, CA, USA) contains the NF- $\kappa$ B enhancer consensus sequences [(TGGGGACTTTCCGC) x5] and $\mathrm{NF}-\kappa \mathrm{B}$-dependent firefly luciferase gene. Cells were seeded in 24-wells plate, and then transiently transfected with pNF- $\kappa$ B-luc plasmids using Lipofectamine 2000 after $24 \mathrm{~h}$. Luciferase activity was measured with the Dual-Luciferase assay system kit (Promega Corp.). 

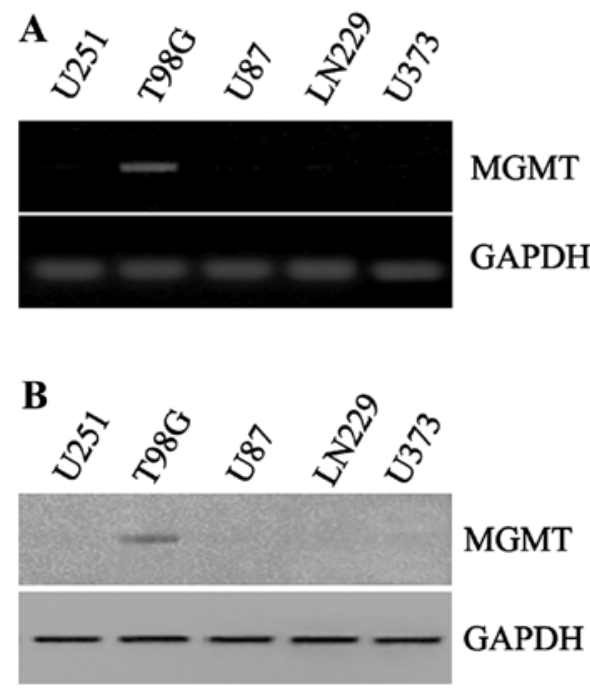

Figure 1. MGMT expression in GBM cell lines. MGMT (A) mRNA and (B) protein are positively expressed in T98G cells while negatively or weakly expressed in the other cells.

Establishment of subcutaneous tumors in a nude mouse model. All animal experiment procedures were carried out according to the regulations and internal biosafety and bioethics guidelines of Tianjin Hospital and Tianjin Huanhu Hospital Medical Ethics Committee. Nude mouse models were established with U373-R GBM cells inoculated subcutaneously into the right flanks of 4-6-week-old female mice. Twenty-four mice were randomized in 4 groups (control, TMZ, SFN alone and the combination of TMZ and SFN) when tumors reached a mass of $\sim 200 \mathrm{~mm}^{3}$ in size. TMZ was given at $50 \mathrm{mg} / \mathrm{kg} /$ day for 5 days/week for 4 cycles. SFN was injected subcutaneously at $50 \mathrm{mg} / \mathrm{kg} / \mathrm{day}$ for 28 consecutive days. Mice were observed daily and euthanized after 5 days of treatment. At the end, all the mice were sacrificed and tumors were collected for further experiments.

Terminal deoxynucleotidyltransferase-mediated dUTP nick end labelling (TUNEL) assay. The apoptosis in the tumor specimens of mouse models from the in vivo study was examined by TUNEL (Roche, Indianapolis, IN, USA) according to the manufacturer's protocol.

Statistical analysis. All of the statistical analyses were evaluated by commercially available software SPSS version 13.0. Differences between the groups were analyzed by using Student's t-test and statistical significance was determined as $\mathrm{P}<0.05$ or $\mathrm{P}<0.01$.

\section{Results}

Expression of MGMT in different GBM cells. To explore the different conditions of MGMT in various types of GBM cells, we firstly detected expression of MGMT mRNA and protein in U251, T98G, U87, LN229 and U373 cells. The expression of MGMT mRNA was high in T98G cells, and very low or hardly detected in other GBM cells (Fig. 1A). Furthermore, the detection of MGMT protein was consistent with mRNA status and much higher in T98G cells (Fig. 1B). As reported,
Table I. Doses required inducing 50\% inhibition of cell growth $\left(\mathrm{IC}_{50}\right)$ in $\mathrm{GBM}$ cell lines treated with TMZ.

\begin{tabular}{|c|c|}
\hline Cell line & $\begin{array}{c}\mathrm{IC}_{50} \\
\mathrm{TMZ}(\mu \mathrm{M})\end{array}$ \\
\hline U251 & 851.3 \\
\hline T98G & 3457.8 \\
\hline U87 & 702.4 \\
\hline LN229 & 954.2 \\
\hline U373 & 483.5 \\
\hline
\end{tabular}

MGMT overexpression was able to resist cell death induced by TMZ. Cellular sensitivity to TMZ in five cell lines was also evaluated after $48 \mathrm{~h}$ of treatment. $\mathrm{IC}_{50}$ values varied between the different cell lines, and the $\mathrm{IC}_{50}$ of $\mathrm{T} 98 \mathrm{G}$ was much high than other cell lines (Table I). Based on the above data, T98G cell line was considered as resistant to TMZ and chosen to carry out the following experiments.

Establishment of TMZ-resistant U373 and U87 GBM cells by chronic exposure to $T M Z$. We then successfully established TMZ-resistant GBM cell models to search the methods of TMZ sensitization. Two TMZ-resistant human glioma cell sublines, U373-R and U87-R, were generated by a stepwise exposure to increasing TMZ concentrations for 6 months. The two established variants showed effective resistance to further TMZ treatment. The $\mathrm{IC}_{50}$ of U373-R and U87-R showed more than 5-fold increase when compared with their parental cell lines (2529.3 vs. $483.5 \mu \mathrm{M}$ and 3657.2 vs. $702.4 \mu \mathrm{M})$ (Fig. 2A). Previous it was reported that most DNA-damaging chemotherapeutic agents including TMZ could activate the transcription of $N F-\kappa B(30)$. We then detected the activity of $\mathrm{NF}-\kappa \mathrm{B}$ in TMZ-inducing cells by transiently transfecting with pNF- $\kappa \mathrm{B}-$ luc reporter plasmids. When compared with control counterparts, $\mathrm{NF}-\kappa \mathrm{B}$ transcription was significant activated in U373-R and U87-R cells (Fig. 2B). At the end of this section, we investigated whether the increase in TMZ resistance in GBM cells was associated with high MGMT expression. PCR and western blot analyses revealed that MGMT content increased significantly at both mRNA and protein levels in the TMZ-resistant cells (Fig. 2C and D). Taken together, these results suggested a link between the onset of TMZ resistance and activity of NF- $\kappa \mathrm{B}$ signaling pathway.

SFN inhibits proliferation of TMZ-resistant GBM cells. SFN has been indicated for the prevention and suppression of tumorigenesis in various solid tumors. Our previous study demonstrated that SFN could effectively enhance TMZ-induced apoptosis by inhibiting miR-21 via $W n t / \beta$-catenin signaling in GBM cells (31). Herein, we aimed to examine the inhibition of growth of SFN in TMZ-resistant GBM cells. The role of SFN in TMZ-resistant cell proliferation was investigated by conducting MTT and colony formation assays. We treated U373-R, U87-R and T98G cells with 5-50 $\mu \mathrm{M}$ for $48 \mathrm{~h}$ and assessed the number of viable cells. The MTT assay showed that SFN had a growth inhibitory effect on all the tumor cell lines in a 

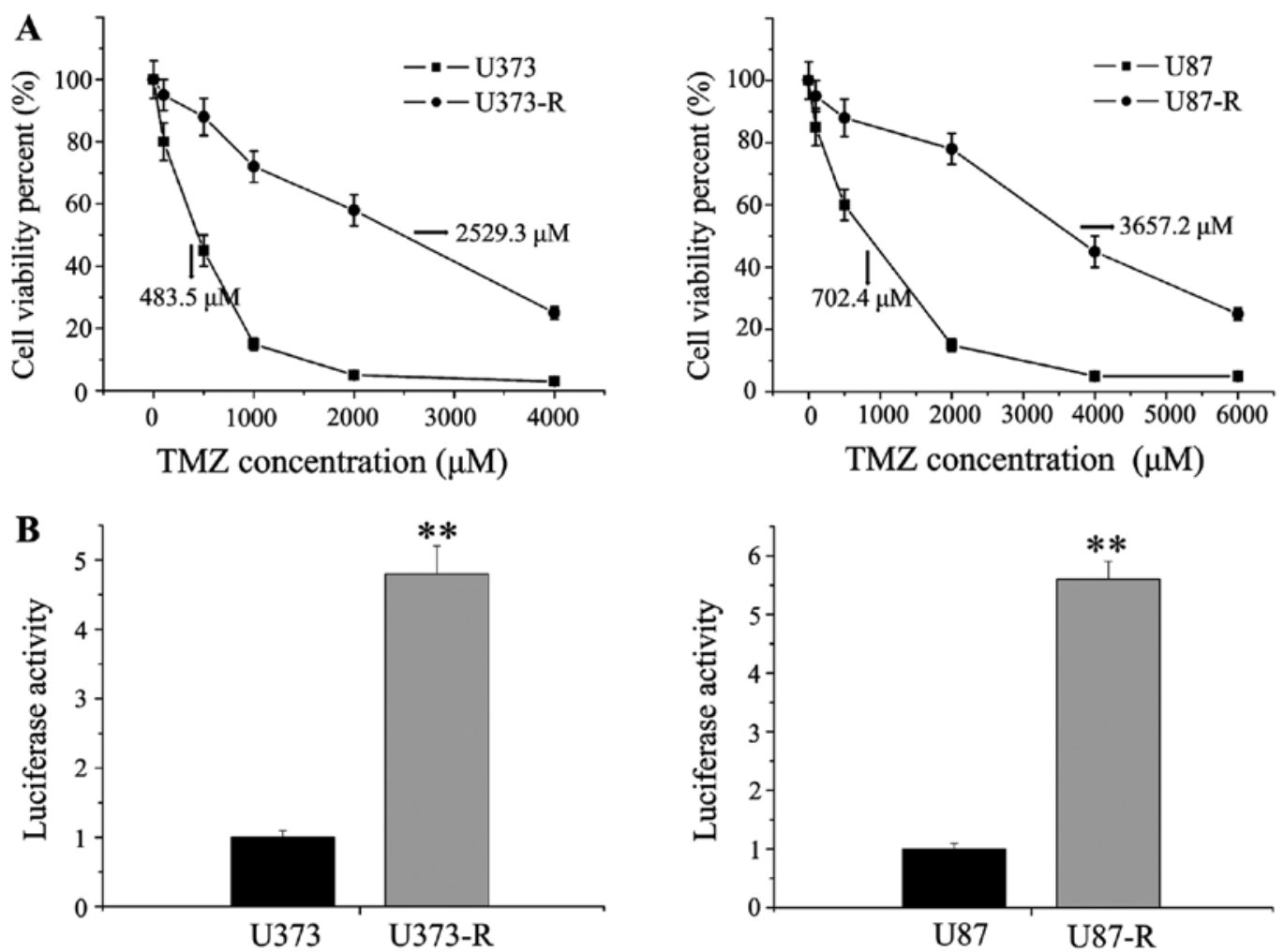

C
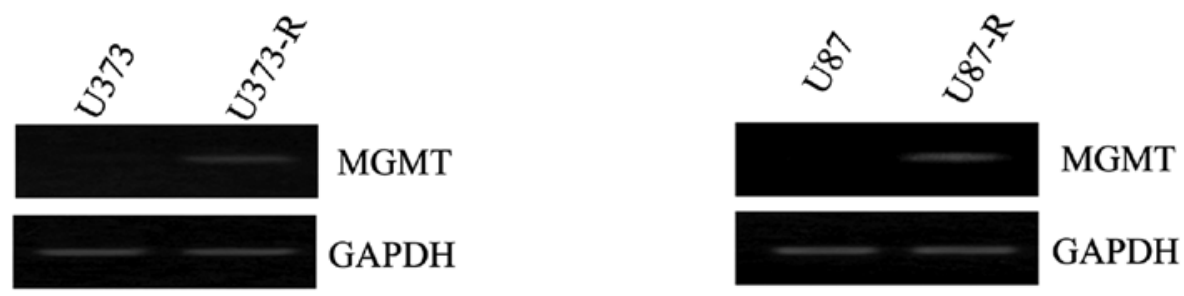

D
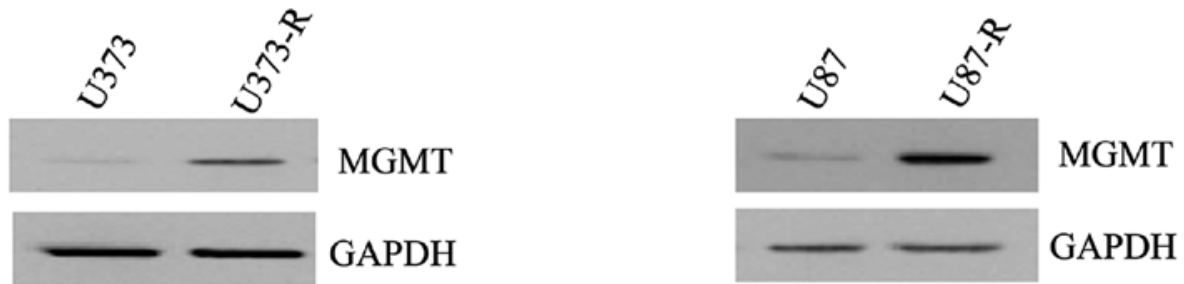

Figure 2. Development of TMZ-resistant GBM cells. (A) $\mathrm{IC}_{50}$ values of U373-R (parental U373) and U87-R (parental U87) cells determined by drug sensitivity assay. (B) NF- $\mathrm{kB}$ transcription activity was significant activated in U373-R and U87-R cells. (C) MGMT mRNA increased in TMZ-resistant cells. (D) MGMT protein increased in TMZ-resistant cells.

dose-dependent manner (Fig. 3A). Next, colony formation assay suggested that cells treated with SFN $(10$ and $25 \mu \mathrm{M})$ for $48 \mathrm{~h}$ formed significantly less colonies than control cells $(\mathrm{P}<0.01)$ (Fig. 3B), suggesting an inhibitory effect of SFN on anchorage-dependent growth of TMZ-resistant cells.

SFN downregulates the expression of MGMT through inhibiting NF- $\kappa B$ in TMZ-resistant GBM cells. To choose the correct dose for the following in vitro combination experiments, the $\mathrm{IC}_{50}$ value of SFN was investigated in these three cell lines. The $\mathrm{IC}_{50}$ of SFN for U373-R, U87-R and T98G was 41.7, 44.8 and $41.5 \mu \mathrm{M}$, respectively (Fig. 4). Based on the above results, concentrations lower than the respective $\mathrm{IC}_{50}$ value of SFN was identified for further study in TMZ-resistant cells. To determine whether SFN as a chemosensitizer in TMZ-resistant GBM was mediated by decreasing the expression of MGMT through inhibiting NF- $\kappa B$, we examined the effects of SFN on NF- $\kappa B$ transcription activity. The U373-R, U87-R and T98G cells were transfected with the NF- $\mathrm{KB}$ reporter plasmids. A range of concentrations of SFN was added to the transfected cells, as observed in Fig 5A, the transcriptional activity of NF- $\kappa B$ was significantly attenuated by SFN in a concentration-dependent manner. A previous study provided evidence that MGMT is a target gene for NF- $\mathrm{BB}(16)$. We then analyzed the expression of MGMT following SFN treatment in TMZ-resistant GBM cells. The PCR and western blot analyses revealed that SFN resulted in decreased expression of MGMT in a dose-dependent manner (Fig. 5B). 

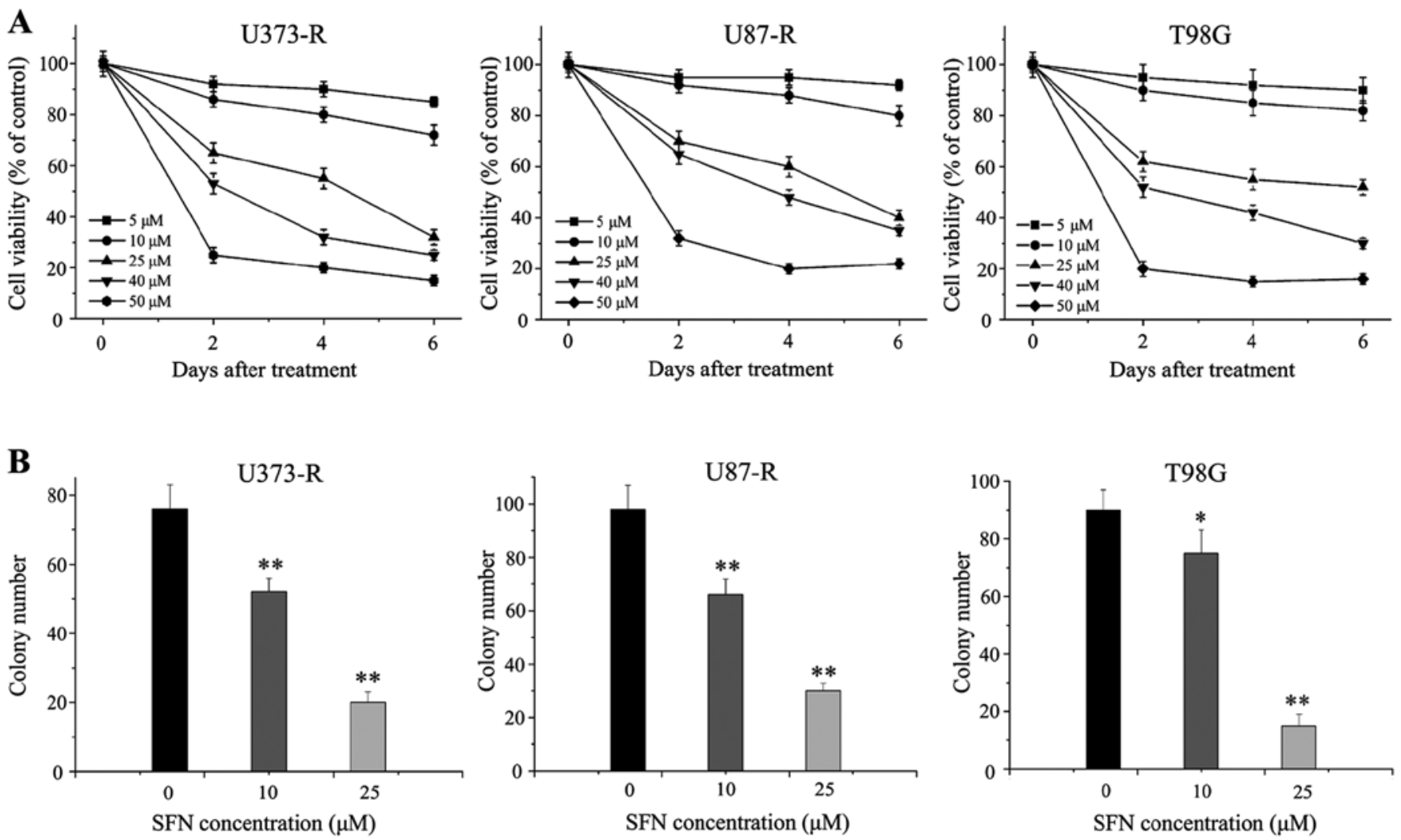

Figure 3. SFN inhibits proliferation of TMZ-resistant GBM cells. (A) SFN remarkably inhibited the cell viability of U373-R, U87-R and T98G cells in a concentration-dependent manner. (B) Less colonies were observed in SFN-treated group (both 10 and $25 \mu \mathrm{M})$ than control cells $(\mathrm{P}<0.01)$

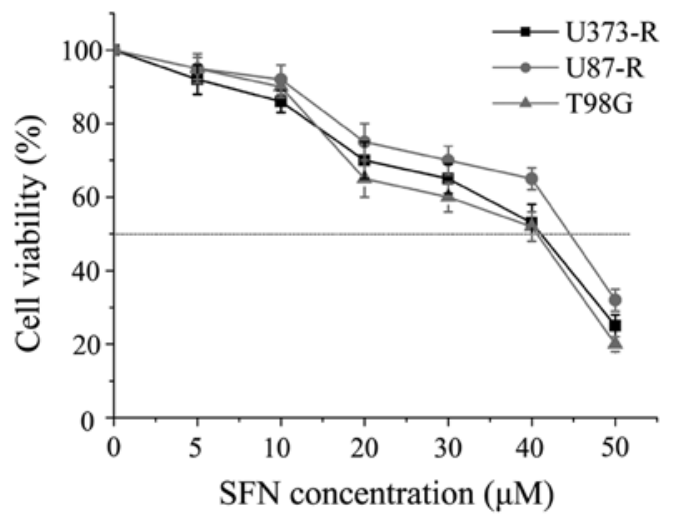

Figure 4. $\mathrm{IC}_{50}$ value of SFN was investigated in TMZ-resistant cell lines.

SFN reverses TMZ-resistant GBM cells to TMZ-induced cytotoxicity in vitro. In order to examine whether SFN can enhance the cytotoxity of TMZ, a series of experiments were conducted, and the dose of $250 \mu \mathrm{M} \mathrm{TMZ}$ was selected, which has been evidenced as no growth inhibitory effects on TMZ-resistant cells. Initially, nonlinear regression of a sigmoid dose response model and combination index (CI) approaches were performed to test drug interaction between SFN and TMZ. The results revealed antagonistic effects $(\mathrm{CI}>1)$ when cells were simultaneously treated with TMZ and each concentration of SFN for T98G, U87-R and U373-R. Nevertheless, the response to concomitant treatment was drastically reversed when the administration order was changed. Synergistic effects $(\mathrm{CI}<1)$ were observed when different concentrations of SFN were used as pretreatment in TMZ-resistant cells for $8 \mathrm{~h}$ before exposure to TMZ. Sequential exposure also resulted in high- dose reduction index (DRI) values suggesting that TMZ doses could be signicantly reduced to achieve comparable cytotoxicity (Table II). The three cell lines were then treated in schedule dependency with the previous $(8 \mathrm{~h})$ exposure to SFN. To identify the synergistic effects of SFN and TMZ on the invasive ability, Transwell Matrigel invasion assay was used in T98G, U87-R and U373-R cell lines. The results suggested that TMZ alone could not inhibit cell invasion, but cells pretreated with different concentrations of SFN combined with TMZ significantly reduced GBM cell invasive capacity (Fig. 6A). We further investigated the effect of SFN on TMZ-inducing apoptosis, TMZ alone did not demonstrate apoptosis induction in the cell lines compared with control, however, the sequential therapy of the SFN and TMZ caused a significant increase of apoptotic death even at lower doses of SFN, suggesting that a synergistic induction of apoptosis developed in the cells co-treated with SFN and TMZ (Fig. 6B). Moreover, caspase-3/7 activity was also considerably elevated after synergism with SFN in TMZ-resistant cells (Fig. 6C). Collectively, these observations provide strong evidence for the role of pretreatment of SFN in reversing TMZ-resistant GBM cells to TMZ.

SFN enhances TMZ chemosensitivity in vivo. To facilitate the in vitro experiments, stable chemo-resistant cell line U373-R was used to establish subcutaneous tumors. We subsequently investigated the synergistic effects of a combination 


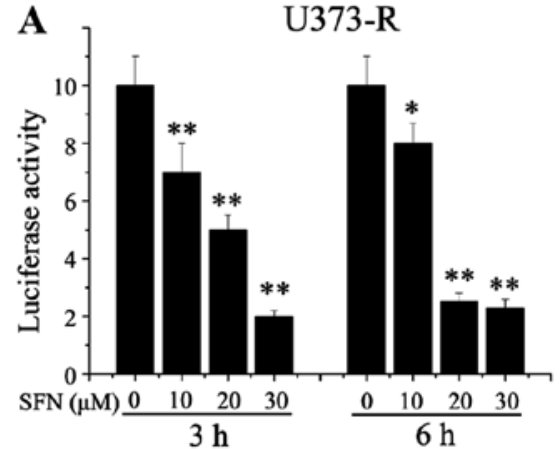

B

U373-R
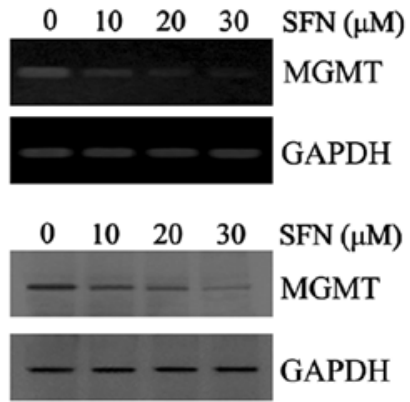

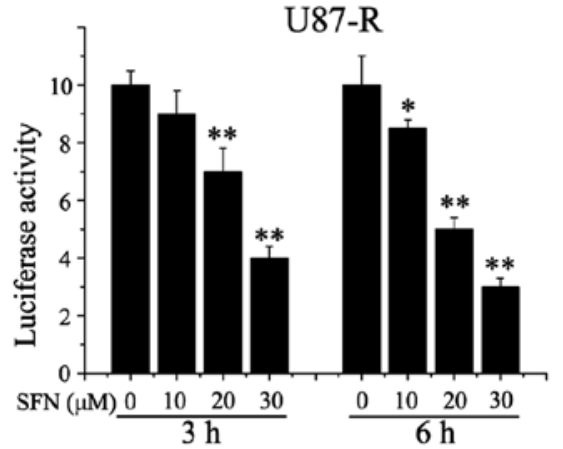

U87-R

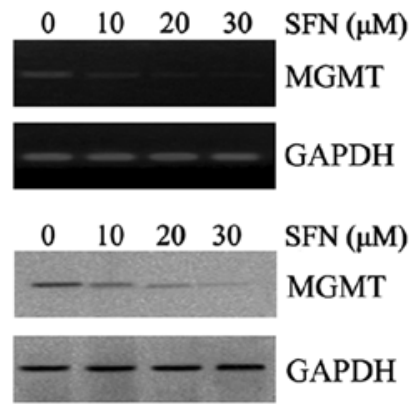

T98G

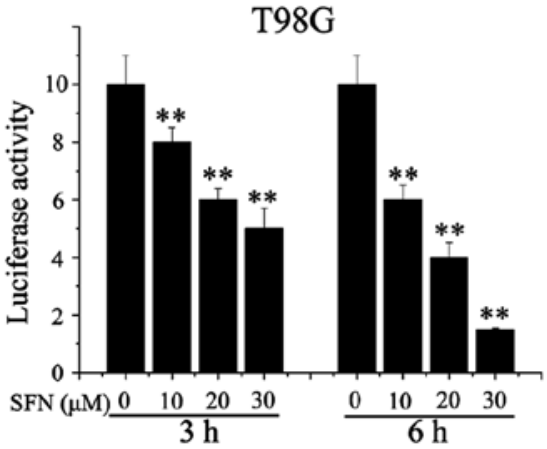

T98G
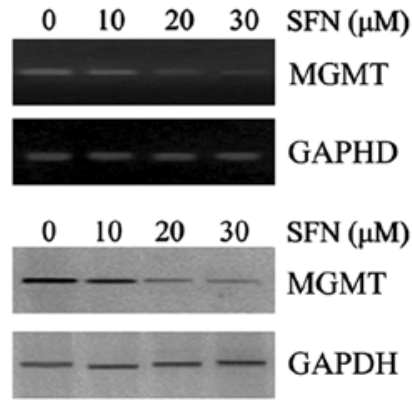

Figure 5. SFN inhibits MGMT expression by NF-kB pathway in TMZ-resistant cell lines. (A) The luciferase reporter assay revealed that SFN significantly repressed NF-кB transcriptional activity. (B) Real-time PCR and western blot analysis were performed to evaluate the level of MGMT.
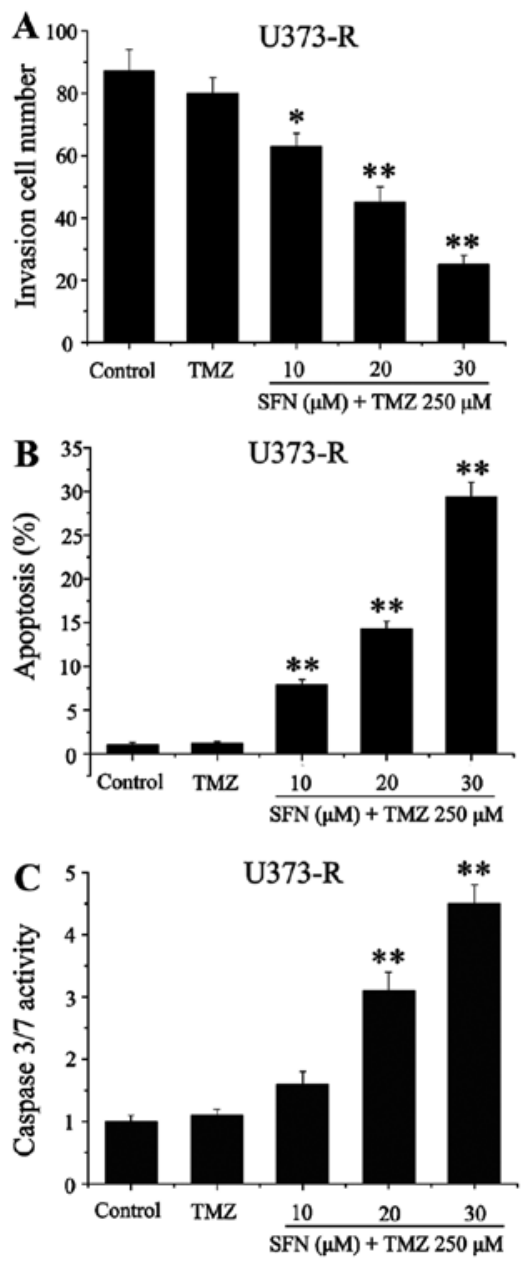
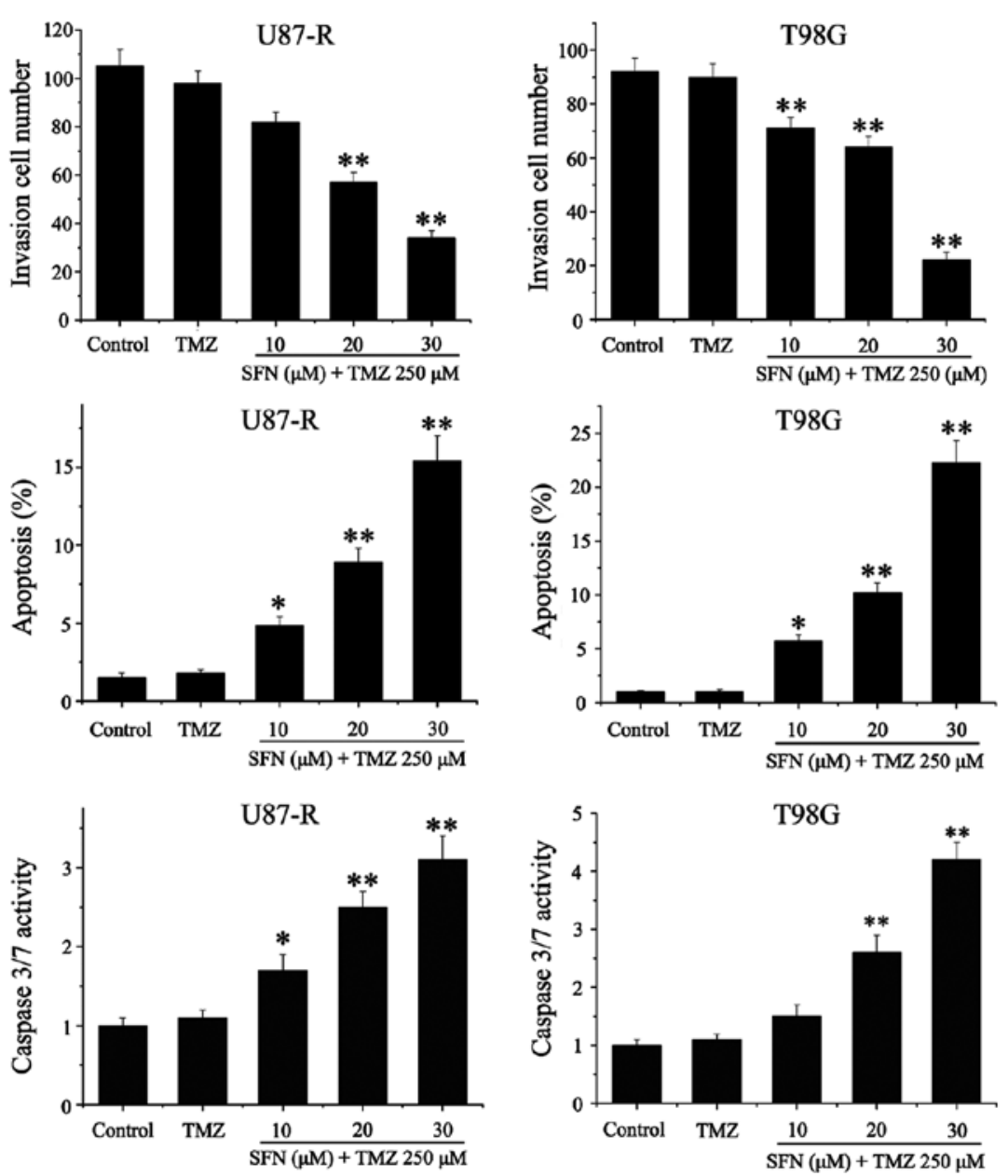

Figure 6. SFN reverses TMZ-resistant cells to TMZ-induced cytotoxicity. (A) Cells pretreated with different concentrations of SFN combined with TMZ significantly reduced the invasive capacity. (B) SFN enhances TMZ-induced apoptosis determined by FACS analysis. (C) Caspase-3/7 activity was elevated after synergism treatment in TMZ-resistant cells. 
Table II. Median dose effect analysis to characterize the interactions between SFN and TMZ.

\begin{tabular}{|c|c|c|c|c|c|c|c|}
\hline \multirow[b]{2}{*}{$\mathrm{SFN}(\mu \mathrm{m})$} & \multicolumn{4}{|c|}{ Concomitant TMZ $(250 \mu \mathrm{m})$} & \multicolumn{3}{|c|}{ Sequential TMZ $(250 \mu \mathrm{m})$} \\
\hline & $\mathrm{AF}$ & $\mathrm{AF}$ & $\mathrm{CI}$ & DRI & $\mathrm{AF}$ & $\mathrm{CI}$ & DRI \\
\hline \multicolumn{8}{|l|}{ U373-R } \\
\hline 5 & 0.02 & 0.01 & 28.12 & 0.29 & 0.27 & 0.93 & 2.63 \\
\hline 10 & 0.07 & 0.05 & 15.73 & 0.37 & 0.41 & 0.78 & 4.67 \\
\hline 20 & 0.13 & 0.09 & 6.54 & 0.64 & 0.79 & 0.54 & 7.85 \\
\hline 30 & 0.25 & 0.14 & 2.45 & 0.98 & 0.85 & 0.15 & 26.79 \\
\hline \multicolumn{8}{|l|}{ U87-R } \\
\hline 5 & 0.01 & 0.01 & 12.57 & 0.57 & 0.29 & 0.98 & 3.45 \\
\hline 10 & 0.02 & 0.02 & 8.65 & 0.98 & 0.37 & 0.73 & 4.13 \\
\hline 20 & 0.03 & 0.02 & 6.42 & 1.21 & 0.45 & 0.65 & 6.27 \\
\hline 30 & 0.05 & 0.04 & 3.96 & 1.45 & 0.67 & 0.27 & 17.89 \\
\hline \multicolumn{8}{|l|}{ T98G } \\
\hline 5 & 0.01 & 0.02 & 57.52 & 0.09 & 0.32 & 0.87 & 1.75 \\
\hline 10 & 0.02 & 0.02 & 21.68 & 0.17 & 0.46 & 0.63 & 3.27 \\
\hline 20 & 0.10 & 0.13 & 11.21 & 0.46 & 0.67 & 0.45 & 5.69 \\
\hline 30 & 0.35 & 0.41 & 7.49 & 0.83 & 0.82 & 0.20 & 18.53 \\
\hline
\end{tabular}

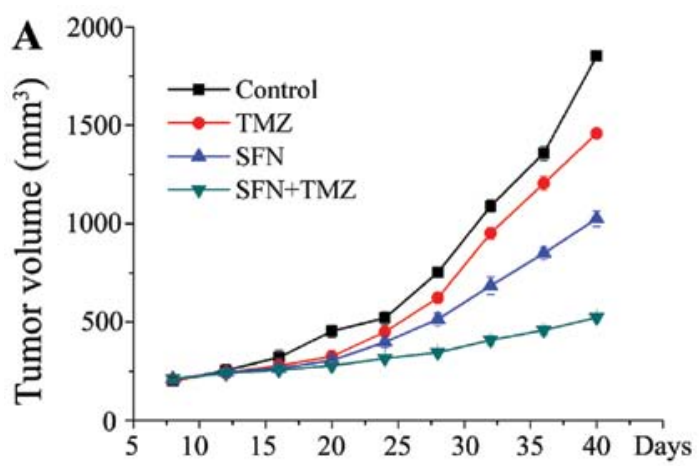

C

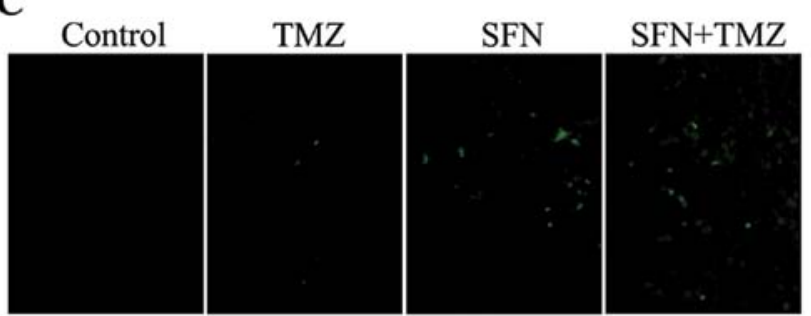

B

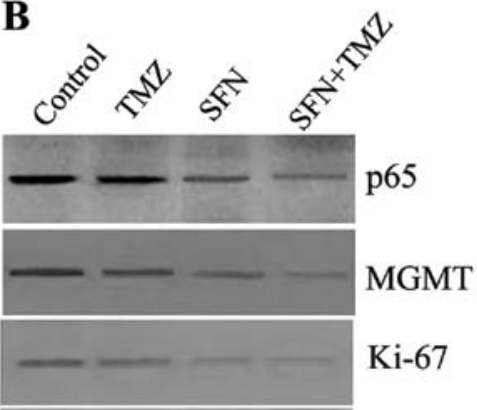

MMP-2

MMP-9

Caspase-3

GAPDH

Figure 7. In vivo tumor mouse model of TMZ-resistant GBM cells shows SFN enhances TMZ chemosensitivity. (A) Inhibition of the growth of U373-R xenografts treated with SFN and TMZ. (B) Expression of NF- $\mathrm{B}$ p65, MGMT, Ki-67, MMP2/9 and caspase-3 in xenografts, as demonstrated by western blot analysis. (C) TUNEL assay was performed to quantify xenograft apoptosis.

of SFN and TMZ in glioma xenograft nude mouse models. In xenograft growth assay, TMZ alone did not effectively suppress growth of the U373-R tumor $(\mathrm{P}>0.05)$. However, SFN alone suppressed tumor growth more significantly than control groups from day $28(\mathrm{P}<0.01)$, and the combination of SFN and TMZ decreased tumor growth to a more significant extent, moreover, the differences in tumor mass of the combined groups were still marked compared with control and TMZ alone group at the termination of the study
$(\mathrm{P}<0.01)$ (Fig. 7A). Therefore, the SFN plus TMZ treatment inhibited tumor growth significantly in the TMZ-resistant glioma xenografts compared with the TMZ alone. To extend these observations, western blot analysis and TUNEL analysis were used to examine solid tumors after 40-day observation. As demonstrated in Fig. 7B, the expression of NF- $\mathrm{B}$ p65 and MGMT protein were significant decreased in combined groups. The protein levels of Ki-67, MMP2/9 and caspase-3 related with the cell proliferation, invasion, and apoptosis in 
combined group were prominently changed which is similar to results obtained from the in vitro study. The TUNEL assay analysis verified the synergistic pro-apoptotic effects of the combination of SFN and TMZ in vivo (Fig. 7C). In conclusion, these data demonstrated that SFN could effectively inhibit TMZ-mediated cell growth and enhance TMZ-mediated cell death in chemo-resistant xenograft nude mouse models.

\section{Discussion}

The inherent chemo- and radio-resistance of GBM are the essential contributing factors that lead to an aggressive clinical course and poor patient outcome. TMZ is widely recognized as the first-line agent in patients with GBM, but the rapid emergence of resistance to majority of GBM is still an urgent issue to tackle $(32,33)$. Many studies have been devoted to sensitize TMZ to improve overall survival of GBM patients. Bevacizumab in combination with TMZ could effectively inhibit tumor cell proliferation, reduce tumor associated inflammation, and induce cancer cell death (34). P4HB inhibition was identified as an effective method in combination with TMZ for the treatment of TMZ-resistant GBM (35). Valparaiso acid can regulate the effectiveness of TMZ-radiochemotherapy and prolong overall survival in patients with newly diagnosed GBM (36).

GBM is considered as a heterogeneous group of tumors with differing cellular lineages, genetic alteration, biological behavior and response to chemotherapeutics. TMZ resistance in GBM also involves different cellular pathways resulting in large number of gene changes $(37,38)$. Although some of the potential mechanisms have not been revealed, persistent $\mathrm{NF}-\kappa \mathrm{B}$ activity can be a result of tumor amplification, invasion and chemo-resistance by targeting transcription of various genes involved in immunoregulation, inflammation, growth, carcinogenesis and apoptosis (39). It is known that NF- $\mathrm{BB}$ is a significant factor involved in MGMT transcription independent of MGMT methylation status and aberrantly activates as part of the DNA damage response. It was previously shown that high $\mathrm{NF}-\kappa \mathrm{B}$ promotes GBM tumor growth and is associated with resistance to alkylating agent-based chemotherapy through the transcriptional activation of genes (16). Several therapeutic inhibitors which can block NF- $\kappa \mathrm{B}$ activation are in development. Dehydroxymethylepoxyquinomicin (DHMEQ) has been reported to be an effective NF- $\kappa B$ inhibitor with antiproliferative properties in GBM (40). Triptolide was able to inhibit NF- $\mathrm{KB}$ signaling in glioma initiating cells, and then synergistically enhances TMZ-induced apoptosis (41). Smac mimetic is reported to sensitize glioblastoma cells to TMZinduced apoptosis, and NF- $\kappa \mathrm{B}$ signaling pathway is identified as a critical mediator (42). Accordingly, inhibiting $N F-\kappa B$ activity can increase sensitivity of GBM cells to alkylating chemotherapeutic treatment and may assist in overcoming treatment-induced chemo-resistance.

Despite these gains, the development of effective therapies to improve the efficacy of TMZ is currently under investigation to achieve durable clinical responses. A new strategy for GBM chemotherapy which is aimed to increase antitumor responses is the combination of natural compound with TMZ (43). Therefore, the present study was performed to detect the role of SFN in sensitizing chemotherapeutic agents of TMZ in
TMZ-resistant glioma cells. We examined different malignant glioma cell lines and exhibited differential expression of the MGMT gene. Moreover, $\mathrm{IC}_{50}$ values varied between the different cell lines, and the $\mathrm{IC}_{50}$ of $\mathrm{T} 98 \mathrm{G}$ was much high than other cell lines. We then successfully established TMZ-resistant glioma cell models to confirm the sensitization of SFN to TMZ.

An extensive amount of studies have shown that chemoprevention property of cruciferous vegetables can directly or indirectly affect survival signaling pathways in cancer cells (44). SFN inhibits TPA-induced NF- $\kappa$ B activation and COX-2 expression by blocking two distinct signaling pathways mediated by ERK1/2-IKKa and NAK-IKKb in MCF-10A cells (45). The incidence of metastatic nodules in the lung with SFN treatment is decreased in transgenic adenocarcinoma of the mouse prostate (TRAMP) (46). SFN can downregulate the expression of $\beta$-catenin through activation of caspase- 3 in human cervical carcinoma HeLa and hepatocarcinoma HepG2 cells. The combination of SFN and chloroquine significantly reduce the incidence as well as size of lymph node metastasis by inhibiting EMT and suppressing proangiogenic cytokine VEGF in prostate cancer compared with control group (22). SFN counteracts aggressiveness of pancreatic cancer driven by dysregulated $\mathrm{Cx} 43$-mediated gap junctional intercellular communication (47).

Here, we provide evidence that SFN could exert antitumor effect on TMZ-resistant cells, and finally reverse chemo-resistance to TMZ by downregulating MGMT expression through $\mathrm{NF}-\kappa \mathrm{B}$ signaling. Initially, we investigated proliferation of the SFN inhibition of TMZ-resistant GBM cells. Next, we revealed function of SFN sensitizing TMZ by blocking NF- $\kappa \mathrm{B}$ signaling in resistant GBM cells, and then, we focused on the synergistic effects of SFN and TMZ in inhibiting proliferation, invasion and inducing apoptosis in vitro and in vivo. In this section, we demonstrated that the key point of synergism is administration of SFN before cells exposure to TMZ. Only sequential schedule of drug administration was efficient in TMZ-resistance cell lines. Pre-existing levels of MGMT protein may be in part a result of response to TMZ which is an important observation in the following in vivo preclinical models or clinical trials.

The novelty of the present study resides in the demonstration that SFN confers increased sensitivity toward TMZ in an NF-кB-dependent manner in TMZ-resistant cells. Our data suggest that long-term exposure to TMZ may result in the development of TMZ resistance and promote malignant phenotypes in human malignant glioma cells. SFN as a potent antitumor agent may reverse TMZ resistance in GBM treatment and successfully translate the experimental knowledge into robust clinical trials, what could be clinically advantageous for GBM patients with intrinsic or acquired drug resistance. This study provides evidence that SFN may be of great clinical value for sensitizing NF- $\kappa \mathrm{B}-\mathrm{MGMT}$-activity cells to TMZ resistance.

\section{Acknowledgements}

This study was supported by the China National Natural Scientific Fund (nos. 81201973, 81502654, 81172596 and 81482814) and Beijing Health System High Level Health Technology Personnel Training Project Foundation. 


\section{References}

1. Wakimoto H, Tanaka S, Curry WT, Loebel F, Zhao D, Tateishi K, Chen J, Klofas LK, Lelic N, Kim JC, et al: Targetable signaling pathway mutations are associated with malignant phenotype in IDH-mutant gliomas. Clin Cancer Res 20: 2898-2909, 2014.

2. Yiin JJ, Hu B, Schornack PA, Sengar RS, Liu KW, Feng H, Lieberman FS, Chiou SH, Sarkaria JN, Wiener EC, et al: ZD6474, a multitargeted inhibitor for receptor tyrosine kinases, suppresses growth of gliomas expressing an epidermal growth factor receptor mutant, EGFRvIII, in the brain. Mol Cancer Ther 9: 929-941, 2010.

3. Yue X, Lan F, Hu M, Pan Q, Wang Q and Wang J: Downregulation of serum microRNA-205 as a potential diagnostic and prognostic biomarker for human glioma. J Neurosurg: Jul 31, 2015 (Epub ahead of print).

4. Yeom SY, Nam DH and Park C: RRAD promotes EGFRmediated STAT3 activation and induces temozolomide resistance of malignant glioblastoma. Mol Cancer Ther 13: 3049-3061, 2014.

5. Loftus JC, Dhruv H, Tuncali S, Kloss J, Yang Z, Schumacher CA, Cao B, Williams BO, Eschbacher JM, Ross JT, et al: TROY (TNFRSF19) promotes glioblastoma survival signaling and therapeutic resistance. Mol Cancer Res 11: 865-874, 2013.

6. Oliva CR, Nozell SE, Diers A, McClugage SG III, Sarkaria JN, Markert JM, Darley-Usmar VM, Bailey SM, Gillespie GY, Landar A, et al: Acquisition of temozolomide chemoresistance in gliomas leads to remodeling of mitochondrial electron transport chain. J Biol Chem 285: 39759-39767, 2010

7. Ramirez YP, Mladek AC, Phillips RM, Gynther M, Rautio J Ross AH, Wheelhouse RT and Sakaria JN: Evaluation of novel imidazotetrazine analogues designed to overcome temozolomide resistance and glioblastoma regrowth. Mol Cancer Ther 14: 111-119, 2014.

8. Park I, Mukherjee J, Ito M, Chaumeil MM, Jalbert LE, Gaensler K, Ronen SM, Nelson SJ and Pieper RO: Changes in pyruvate metabolism detected by magnetic resonance imaging are linked to DNA damage and serve as a sensor of temozolomide response in glioblastoma cells. Cancer Res 74: 7115-7124, 2014

9. Smalley S, Chalmers AJ and Morley SJ: mTOR inhibition and levels of the DNA repair protein MGMT in T98G glioblastoma cells. Mol Cancer 13: 144, 2014.

10. Gupta SK, Mladek AC, Carlson BL, Boakye-Agyeman F, Bakken KK, Kizilbash SH, Schroeder MA, Reid J and Sarkaria JN: Discordant in vitro and in vivo chemopotentiating effects of the PARP inhibitor veliparib in temozolomidesensitive versus-resistant glioblastoma multiforme xenografts Clin Cancer Res 20: 3730-3741, 2014.

11. Cen L, Carlson BL, Pokorny JL, Mladek AC, Grogan PT, Schroeder MA, Decker PA, Anderson SK, Giannini C, Wu W, et al: Efficacy of protracted temozolomide dosing is limited in MGMT unmethylated GBM xenograft models. Neuro Oncol 15: 735-746, 2013

12. Melguizo C, Prados J, González B, Ortiz R, Concha A, Alvarez PJ, Madeddu R, Perazzoli G, Oliver JA, López R, et al: MGMT promoter methylation status and MGMT and CD133 immunohistochemical expression as prognostic markers in glioblastoma patients treated with temozolomide plus radiotherapy. J Transl Med 10: 250, 2012.

13. Etcheverry A, Aubry M, Idbaih A, Vauleon E, Marie Y, Menei P, Boniface R, Figarella-Branger D, Karayan-Tapon L, Quillien V, et al: DGKI methylation status modulates the prognostic value of MGMT in glioblastoma patients treated with combined radiochemotherapy with temozolomide. PLoS One 9: e104455, 2014.

14. Nguyen SA, Stechishin OD, Luchman HA, Lun XQ, Senger DL, Robbins SM, Cairncross JG and Weiss S: Novel MSH6 mutations in treatment-naïve glioblastoma and anaplastic oligodendroglioma contribute to temozolomide resistance independently of MGMT promoter methylation. Clin Cancer Res 20: 4894-4903, 2014.

15. Lee KE: Immunohistochemical assessment of O(6)-methylguanine-DNA methyltransferase (MGMT) and its relationship with $\mathrm{p} 53$ expression in endometrial cancers. J Cancer Prev 18: 351-354, 2013

16. Lavon I, Fuchs D, Zrihan D, Efroni G, Zelikovitch B, Fellig Y and Siegal T: Novel mechanism whereby nuclear factor kappaB mediates DNA damage repair through regulation of O(6)-methylguanine-DNA-methyltransferase. Cancer Res 67: 8952-8959, 2007.
17. Persano L, Pistollato F, Rampazzo E, Della Puppa A, Abbadi S, Frasson C, Volpin F, Indraccolo S, Scienza R and Basso G: BMP2 sensitizes glioblastoma stem-like cells to Temozolomide by affecting HIF-1 $\alpha$ stability and MGMT expression. Cell Death Dis 3: e412, 2012.

18. Janssens S, Tinel A, Lippens S and Tschopp J: PIDD mediates NF-kappaB activation in response to DNA damage. Cell 123: 1079-1092, 2005.

19. Rawat N, Alhamdani A, McAdam E, Cronin J, Eltahir Z, Lewis P, Griffiths P, Baxter JN and Jenkins GJ: Curcumin abrogates bile-induced NF- $\kappa \mathrm{B}$ activity and DNA damage in vitro and suppresses NF- $\kappa \mathrm{B}$ activity whilst promoting apoptosis in vivo, suggesting chemopreventative potential in Barrett's oesophagus. Clin Transl Oncol 14: 302-311, 2012.

20. Dong QG, Sclabas GM, Fujioka S, Schmidt C, Peng B, Wu T, Tsao MS, Evans DB, Abbruzzese JL, McDonnell TJ, et al: The function of multiple IkappaB: NF-kappaB complexes in the resistance of cancer cells to Taxol-induced apoptosis. Oncogene 21: 6510-6519, 2002.

21. Li F and Sethi G: Targeting transcription factor NF-kappaB to overcome chemoresistance and radioresistance in cancer therapy. Biochim Biophys Acta 1805: 167-180, 2010.

22. Vyas AR, Hahm ER, Arlotti JA, Watkins S, Stolz DB, Desai D, Amin S and Singh SV: Chemoprevention of prostate cancer by d,1-sulforaphane is augmented by pharmacological inhibition of autophagy. Cancer Res 73: 5985-5995, 2013.

23. Cornblatt BS, Ye L, Dinkova-Kostova AT, Erb M, Fahey JW, Singh NK, Chen MS, Stierer T, Garrett-Mayer E, Argani P, et al: Preclinical and clinical evaluation of sulforaphane for chemoprevention in the breast. Carcinogenesis 28: 1485-1490, 2007.

24. Lenzi M, Fimognari C and Hrelia P: Sulforaphane as a promising molecule for fighting cancer. Cancer Treat Res 159: 207-223, 2014

25. Pledgie-Tracy A, Sobolewski MD and Davidson NE: Sulforaphane induces cell type-specific apoptosis in human breast cancer cell lines. Mol Cancer Ther 6: 1013-1021, 2007.

26. Lin LC, Yeh CT, Kuo CC, Lee CM, Yen GC, Wang LS, Wu CH, Yang WC and Wu AT: Sulforaphane potentiates the efficacy of imatinib against chronic leukemia cancer stem cells through enhanced abrogation of Wnt/ $\beta$-catenin function. J Agric Food Chem 60: 7031-7039, 2012.

27. Chaudhuri D, Orsulic S and Ashok BT: Antiproliferative activity of sulforaphane in Akt-overexpressing ovarian cancer cells. Mol Cancer Ther 6: 334-345, 2007

28. Lan F, Yu H, Hu M, Xia T and Yue X: miR-144-3p exerts anti-tumor effects in glioblastoma by targeting c-Met. J Neurochem 135: 274-286, 2015.

29. Yamini B, Yu X, Dolan ME, Wu MH, Darga TE, Kufe DW and Weichselbaum RR: Inhibition of nuclear factor-kappaB activity by temozolomide involves O6-methylguanine induced inhibition of p65 DNA binding. Cancer Res 67: 6889-6898, 2007.

30. Caporali S, Levati L, Graziani G, Muzi A, Atzori MG, Bonmassar E, Palmieri G, Ascierto PA and D'Atri S: NF- $\kappa \mathrm{B}$ is activated in response to temozolomide in an AKT-dependent manner and confers protection against the growth suppressive effect of the drug. J Transl Med 10: 252, 2012.

31. Lan F, Pan Q, Yu H and Yue X: Sulforaphane enhances temozolomide-induced apoptosis because of down-regulation of miR-21 via Wnt/ $\beta$-catenin signaling in glioblastoma. J Neurochem 134: 811-818, 2015.

32. Li R, Tang D, Zhang J, Wu J, Wang L and Dong J: The temozolomide derivative 2T-P400 inhibits glioma growth via administration route of intravenous injection. J Neurooncol 116: 25-30, 2014.

33. Grossman SA, Ye X, Piantadosi S, Desideri S, Nabors LB, Rosenfeld M and Fisher J; NABTT CNS Consortium: Survival of patients with newly diagnosed glioblastoma treated with radiation and temozolomide in research studies in the United States. Clin Cancer Res 16: 2443-2449, 2010.

34. Grossman R, Rudek MA, Brastianos H, Zadnik P, Brem H, Tyler B and Blakeley JO: The impact of bevacizumab on temozolomide concentrations in intracranial U87 gliomas. Cancer Chemother Pharmacol 70: 129-139, 2012

35. Sun S, Lee D, Ho AS, Pu JK, Zhang XQ, Lee NP, Day PJ, Lui WM, Fung CF and Leung GK: Inhibition of prolyl 4-hydroxylase, beta polypeptide (P4HB) attenuates temozolomide resistance in malignant glioma via the endoplasmic reticulum stress response (ERSR) pathways. Neuro Oncol 15: 562-577, 2013. 
36. Weller M, Gorlia T, Cairncross JG, van den Bent MJ, Mason W, Belanger K, Brandes AA, Bogdahn U, MacDonald DR, Forsyth $\mathrm{P}$, et al: Prolonged survival with valproic acid use in the EORTC/NCIC temozolomide trial for glioblastoma. Neurology 77: 1156-1164, 2011.

37. Liu X, Han EK, Anderson M, Shi Y, Semizarov D, Wang G, McGonigal T, Roberts L, Lasko L, Palma J, et al: Acquired resistance to combination treatment with temozolomide and ABT-888 is mediated by both base excision repair and homologous recombination DNA repair pathways. Mol Cancer Res 7: 1686-1692, 2009.

38. Ciechomska IA, Gabrusiewicz K, Szczepankiewicz AA and Kaminska B: Endoplasmic reticulum stress triggers autophagy in malignant glioma cells undergoing cyclosporine a-induced cell death. Oncogene 32: 1518-1529, 2013.

39. Tergaonkar V, Pando M, Vafa O, Wahl G and Verma I: p53 stabilization is decreased upon NFkappaB activation: A role for NFkappaB in acquisition of resistance to chemotherapy. Cancer Cell 1: 493-503, 2002.

40. Brassesco MS, Roberto GM, Morales AG, Oliveira JC, Delsin LE, Pezuk JA, Valera ET, Carlotti CG Jr, Rego EM, de Oliveira HF, et al: Inhibition of NF- $\kappa \mathrm{B}$ by dehydroxymethylepoxyquinomicin suppresses invasion and synergistically potentiates temozolomide and $\gamma$-radiation cytotoxicity in glioblastoma cells. Chemother Res Pract 2013: 593020, 2013.

41. Sai K, Li WY, Chen YS, Wang J, Guan S, Yang QY, Guo CC, Mou YG, Li WP and Chen ZP: Triptolide synergistically enhances temozolomide-induced apoptosis and potentiates inhibition of NF- $\kappa \mathrm{B}$ signaling in glioma initiating cells. Am J Chin Med 42: 485-503, 2014.
42. Wagner L, Marschall V, Karl S, Cristofanon S, Zobel K, Deshayes K, Vucic D, Debatin KM and Fulda S: Smac mimetic sensitizes glioblastoma cells to Temozolomide-induced apoptosis in a RIP1- and NF-кB-dependent manner. Oncogene 32: 988-997, 2013.

43. Turrini E, Ferruzzi L and Fimognari C: Natural compounds to overcome cancer chemoresistance: Toxicological and clinical issues. Expert Opin Drug Metab Toxicol 10: 1677-1690, 2014

44. Asakage M, Tsuno NH, Kitayama J, Tsuchiya T, Yoneyama S, Yamada J, Okaji Y, Kaisaki S, Osada T, Takahashi K, et al: Sulforaphane induces inhibition of human umbilical vein endothelial cells proliferation by apoptosis. Angiogenesis 9: 83-91, 2006.

45. Kim HN, Kim DH, Kim EH, Lee MH, Kundu JK, Na HK, Cha YN and Surh YJ: Sulforaphane inhibits phorbol ester-stimulated IKK-NF- $\kappa \mathrm{B}$ signaling and COX-2 expression in human mammary epithelial cells by targeting NF- $\kappa \mathrm{B}$ activating kinase and ERK. Cancer Lett 351: 41-49, 2014.

46. Singh SV, Warin R, Xiao D, Powolny AA, Stan SD, Arlotti JA, Zeng Y, Hahm ER, Marynowski SW, Bommareddy A, et al: Sulforaphane inhibits prostate carcinogenesis and pulmonary metastasis in TRAMP mice in association with increased cytotoxicity of natural killer cells. Cancer Res 69: 2117-2125, 2009.

47. Forster T, Rausch V, Zhang Y, Isayev O, Heilmann K, Schoensiegel F, Liu L, Nessling M, Richter K, Labsch S, et al: Sulforaphane counteracts aggressiveness of pancreatic cancer driven by dysregulated $\mathrm{Cx} 43$-mediated gap junctional intercellular communication. Oncotarget 5: 1621-1634, 2014. 